\title{
Carbon movement and assimilation by invertebrates in estuarine habitats at a scale of metres
}

\author{
Michaela A. Guest ${ }^{1,3}$, Rod M. Connolly ${ }^{1,3, *}$, Neil R. Loneragan ${ }^{2,3}$ \\ ${ }^{1}$ Centre for Aquatic Processes and Pollution, and School of Environmental and Applied Sciences, Gold Coast Campus, \\ Griffith University, PMB 50, Gold Coast Mail Centre, Queensland 9726, Australia \\ ${ }^{2}$ CSIRO Marine Research, PO Box 120, Cleveland, Queensland 4163, Australia \\ ${ }^{3}$ The Cooperative Research Centre for Coastal Zone, Estuary and Waterway Management, Queensland 4068, Australia
}

\begin{abstract}
Theories of large-scale (kilometres) movement of carbon within and from estuaries are often not supported by empirical data, and this provided the basis for a smaller-scale (i.e. $<100 \mathrm{~m}$ ) analysis of carbon movement and assimilation between adjacent habitats. We tested 3 models that potentially explained the movement and assimilation of carbon by resident animals in estuarine habitats at different spatial scales: coarse ( $>30 \mathrm{~m})$, intermediate $(2$ to $30 \mathrm{~m})$ and fine $(<2 \mathrm{~m})$. The carbon stable isotope signatures of $2 \mathrm{crab}$ and 2 gastropod species were measured at different positions in saltmarsh and mangrove habitats (centre, intermediate and edge in the saltmarsh, intermediate and centre positions in adjacent mangroves) at 5 sites. The $\delta^{13} \mathrm{C}$ signatures of crabs collected from the saltmarsh $(-15.6 \pm 0.2 \%$ o) were significantly more enriched than those of crabs from the mangrove habitat $(-22.1 \pm 0.3 \%)$, but did not differ between positions within each habitat. The $\delta^{13} \mathrm{C}$ signatures of crabs in the saltmarsh were similar to those of the dominant macrophyte, the salt couch grass Sporobolus virginicus $(-14.9 \pm 0.1 \%)$. The $\delta^{13} \mathrm{C}$ signatures of crabs in the mangrove habitat were enriched relative to those of the mangroves $(-27.6 \pm 0.2 \%)$, but were similar to those of the microphytobenthos in that habitat $(-24.6 \pm 0.7 \%)$. The crabs thus fitted the fine-scale model of assimilation of carbon produced in their immediate vicinity, although the signatures for crabs in the mangrove habitat were also consistent with a food source comprising a mixture of mangroves and a more enriched source, possibly the salt couch grass $S$. virginicus. Gastropods were found only in the saltmarsh habitat. Their $\delta^{13} \mathrm{C}$ signatures did not differ among central and intermediate positions $\left(-15.3 \pm 0.2 \%\right.$ ) but were lower at edge positions $(-17.0 \pm 0.1 \%)$. The $\delta^{13} \mathrm{C}$ signatures of gastropods indicated assimilation of carbon from sources 2 to $15 \mathrm{~m}$ away, at the lower end of the intermediate scale. The extent of carbon movement and assimilation varies among estuaries, and our results show that in some situations it occurs at scales much smaller than previously realised.
\end{abstract}

KEY WORDS: Trophic ecology $\cdot$ Stable isotope analysis $\cdot$ Estuaries $\cdot$ Crustacea $\cdot$ Gastropoda

\section{INTRODUCTION}

The source of an animal's food is a central organising theme in ecology (Polis et al. 1997). The movement of potential energy sources across spatial boundaries is influenced by the structural complexity of the landscape (Holt 2002) and the permeability of habitat boundaries (Marquet et al. 1993), not least in aquatic systems. In aquatic systems the potential connection between seemingly fragmented landscapes is en- hanced by the role of water as a vector for nutrient, detritus and animal transport (Polis et al. 1997). In marine systems, the study of large-scale movement of carbon produced inshore to offshore environments, termed 'outwelling' (Odum 1979), has provided the foundation for a closer analysis of the scale of carbon movement in marine and estuarine systems.

Early studies of outwelling focused on the role of saltmarshes (predominantly in the USA) in supporting offshore fisheries productivity, with the term subse- 
quently also applied to mangroves. However, empirical evidence for large-scale movement of carbon from intertidal habitats is variable. In some estuaries carbon either does not move very far or moves but is not assimilated by consumers. For example, a study in South Africa demonstrated only minor contributions of carbon from a high marsh to offshore waters (Taylor \& Allanson 1995). In Malaysia, mangrove carbon was detected several kilometres offshore but was not assimilated by consumers (Rodelli et al. 1984). In a review of mangrove outwelling, Lee (1995) summarised the role of mangroves to include net exporters, net importers, and sinks that retain large proportions of the litter production for in situ consumption.

The lack of evidence of large-scale movement and assimilation of carbon from inshore to offshore in some estuaries (e.g. Dittel et al. 2000) led to studies of the movement of carbon between inshore habitats. Marguillier et al. (1997) examined the trophic links between seagrass and mangroves separated by $\sim 1 \mathrm{~km}$, and found evidence to suggest the movement and assimilation of mangrove carbon to nearby seagrass consumers. The shift in focus from carbon transfer between inshore and offshore to exchange between inshore habitats also led to a reduction in the scale at which carbon movement and assimilation was examined, from several kilometres to $\leq 1 \mathrm{~km}$. A recent study examining assimilation of carbon by consumers at a creek site and a river site separated by hundreds of metres found that the movement and assimilation of carbon might be more appropriately examined at even smaller scales than had previously been considered (Hsieh et al. 2002).

Stable isotope analysis of carbon is an effective method of tracing energy transfer from autotrophs to consumers (e.g. Deegan \& Garritt 1997, Loneragan et al. 1997, Chong et al. 2001). This method is able to distinguish among carbon sources, where autotrophs have distinct ratios of ${ }^{13} \mathrm{C} /{ }^{12} \mathrm{C}$, and consumers assume the ratio of their food source (Peterson \& Fry 1987). The saltmarsh and mangrove habitats used in this study are ideally suited to this approach, as the ${ }^{13} \mathrm{C} /{ }^{12} \mathrm{C}$ ratios of the dominant autotrophs in each habitat are clearly separated. Stable isotope analysis of carbon also has advantages over other techniques used to study food-web processes as the $\delta^{13} \mathrm{C}$ values of consumers experience only minor enrichment across trophic levels (typically $<1 \%$; McCutchan et al. 2003). This means that despite multiple trophic shifts (for example via a microbial loop or through the consumption of small invertebrates), stable isotope analysis of carbon can trace the original (autotrophic) source of carbon and therefore does not rely on the direct consumption of plant material by the study organism.

In this study, we used stable isotope analysis to test 3 potential models of carbon movement and its assimilation by invertebrates in adjacent saltmarsh and mangrove habitats, where the carbon signatures of autotrophs from each habitat could be distinguished (Fig. 1). The coarse-scale model (Model a) comprises large-scale movement $(>30 \mathrm{~m})$ of carbon and therefore no pattern in carbon isotope signatures of consumers across the habitat boundary. The intermediate-scale model (Model b) comprises more limited carbon movement and assimilation across the habitat boundary (2 to $30 \mathrm{~m}$ ): the prediction of this model is that $\delta^{13} \mathrm{C}$ signatures of animals will be influenced by their position within a habitat - the closer to an adjacent habitat, the greater the contribution of carbon from the adjacent habitat. The fine-scale model (Model c) predicts that there is no movement and assimilation of carbon across the habitat boundary: in this scenario, an animal obtains its carbon from autotrophs in its immediate vicinity. The coarse model represents the current understanding of estuarine food webs; the intermediate and fine-scale models represent patterns and extents of movement and assimilation not addressed in previous studies. The labels 'coarse', 'intermediate' and 'fine' were chosen to avoid confusion with other terms such as 'local', which is used in the literature to refer to kilometre-scale movement of carbon.

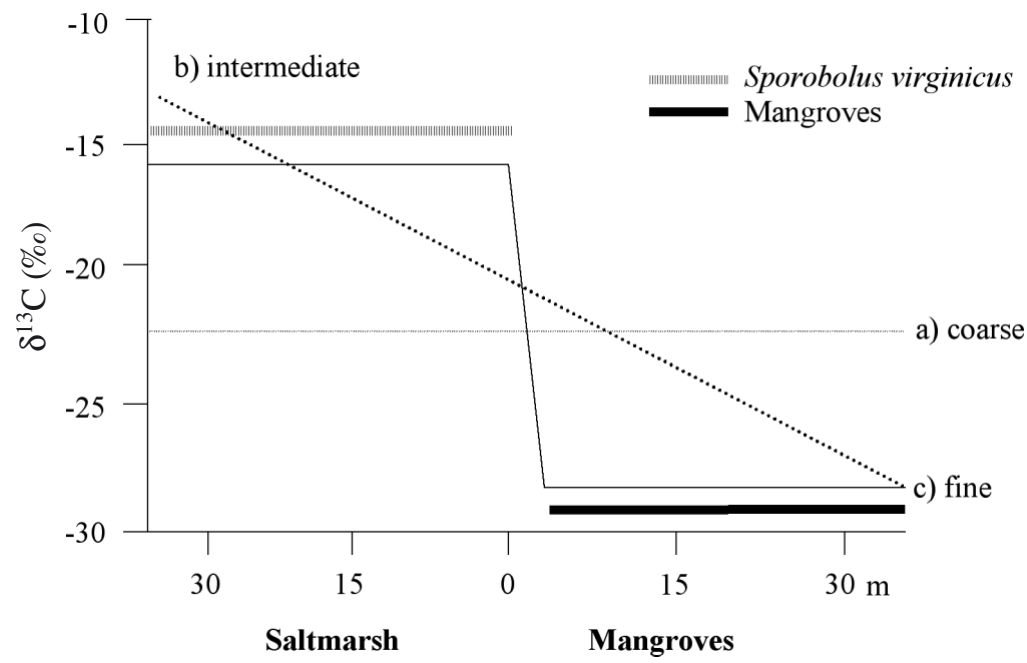

Fig. 1. Patterns of animal isotope signatures predicted by 3 possible models explaining carbon movement and assimilation between adjacent estuarine habitats at different spatial scales: coarse $(>30 \mathrm{~m}$ : Model a), intermediate ( 2 to $30 \mathrm{~m}$ : Model b), and fine $(<2 \mathrm{~m}$ : Model c) 


\section{MATERIALS AND METHODS}

We sampled 5 saltmarshes adjacent to mangroves and dominated by the salt couch grass Sporobolus virginicus, in March 2003 in southern Moreton Bay, Queensland, Australia (Fig. 2). The dominant mangrove species was Avicennia marina, but occasional examples of Ceriops tagal, Rhizophora stylosa and Bruguiera gymnorhiza also occurred. Saltmarshes form part of a complex mosaic of estuarine habitats common in this region, and were defined visually by the presence of discrete habitat boundaries marked by an abrupt change in vegetation type (i.e. mangroves and water). The areas of the saltmarsh habitat were between 1 and $2 \mathrm{ha}$, and adjacent mangroves were at least 10 ha in extent. The marshes selected were lowlying and were inundated on at least 1 high tide each day for 2 out of 4 wk during the sampling period.

We chose 2 crab species, Australoplax tridentata (Ocypodidae) and Parasesarma erythrodactyla (Grapsidae), and 2 gastropod species, Salinator solida (Pulmonata: Aphibolidae) and Ophicardelus quoyi (Pulmonata: Ellobiidae) for analysis. The crabs were chosen because they are found in both saltmarshes and mangroves, and whilst there is little documentation of the movement of A. tridentata and P. erythrodactyla, they are considered to be faithful to their burrows (M. A. Guest pers. obs.) and are therefore assumed to have restricted home ranges. The gastropods were chosen because anecdotal evidence also suggests they are of limited mobility. The crabs are thought to consume detritus, which consists of plant material, microbes and small invertebrates; the snails are either grazers and/or detritivores.

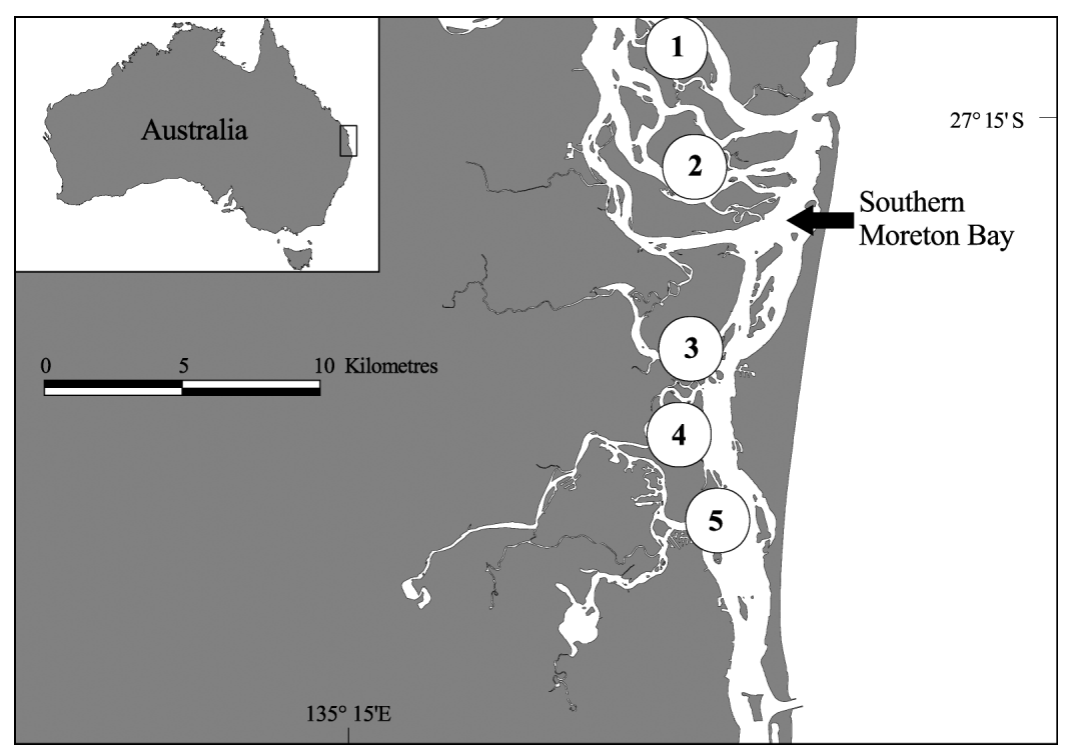

Fig. 2. Study area in southern Moreton Bay showing sampling sites (1 to 5) of saltmarsh adjacent to mangroves
At each of the 5 sites (Fig. 2), 5 positions across the 2 habitat types were chosen: centre and intermediate positions in each habitat, and a position near the saltmarsh/mangrove interface. This last position is labelled 'edge', but was actually $2 \mathrm{~m}$ inside the saltmarsh habitat (Fig. 3). Setting the edge position slightly inside the saltmarsh gave us more resolution of carbon movement than having it exactly on the interface between habitats. Positions were separated by about $15 \mathrm{~m}$, so the central positions were about $30 \mathrm{~m}$ inside each habitat. We collected 3 samples of both crab species from each position (i.e. 15 samples per site per species), and 3 samples of both gastropod species were collected from central, intermediate and edge positions in the saltmarsh habitat at 3 sites, but no gastropods were collected from mangrove habitats. Each sample consisted of several individuals collected immediately adjacent to a randomly selected point at each position in the habitat. We collected 3 samples of live Sporobolus virginicus from central and edge positions at each site (i.e. 6 samples at each site), and 3 samples of fresh leaves for each mangrove species from intermediate and central positions. Apart from the dominant autotrophs, numerous but inconspicuous algal and cyanobacteria cells are present in the superficial sediment of both habitats; 1 sample of this microphytobenthos (MPB) was collected at the intermediate position in the saltmarsh and in the mangrove habitat at each site, adjacent to where collections of crabs and gastropods were made, by scraping the top $1 \mathrm{~cm}$ of sediment from the mud surface.

Gastropod samples were allowed approximately $8 \mathrm{~h}$ before freezing for extrusion of gut contents. All other samples were frozen immediately after collection. Samples were thawed prior to processing. The exoskel-eton and shell were removed from the crabs and gastropods, the gut removed from the crab, and soft flesh selected from both for analysis. MPB samples were washed through $53 \mu \mathrm{m}$ mesh to remove infauna, and material passing through the mesh was then washed through $5 \mu \mathrm{m}$ mesh. Material retained on this mesh was added $(9 \mathrm{ml})$ to a centrifuge tube containing $21 \mathrm{ml}$ of colloidal silica (LUDOX ${ }^{\mathrm{TM}}$ AM30, density $=1.21$ ) and centrifuged at $10000 \mathrm{rpm}$ for $10 \mathrm{~min}$. A band of diatoms, some organic matter and silica particles formed at the top of the centrifuge tube. This band was removed and again washed through a $5 \mu \mathrm{m}$ mesh to remove the silica and any remaining microbes. Inspection of 


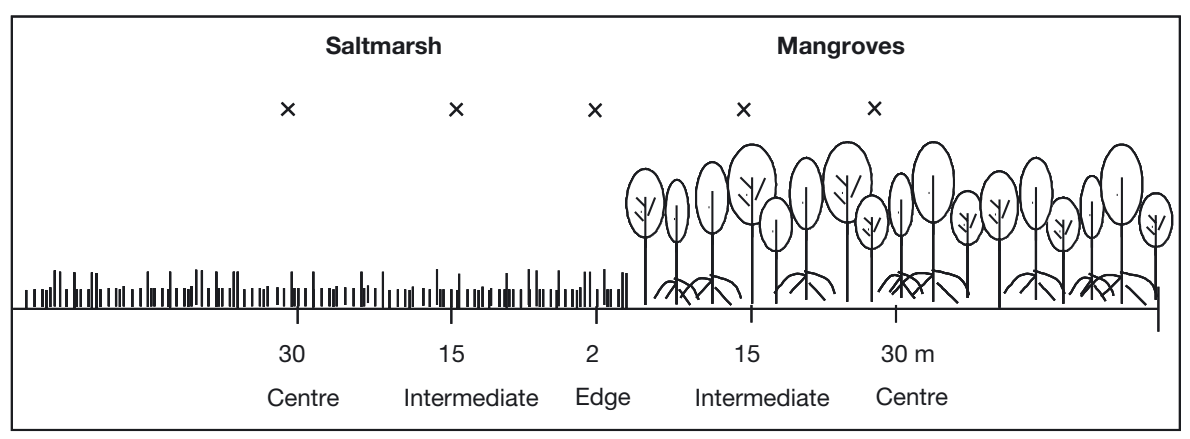

Fig. 3. Sampling transect for each site of saltmarsh adjacent to mangroves. Sampling positions transecting the 2 habitat types are: centre, intermediate, edge (saltmarsh) and intermediate and centre (mangroves). $\times$ : Replicates for each position within each habitat ( $n=3$ for each position at each site) samples showed that they consisted predominantly of microalgae (mainly diatoms) with occasional contamination by very fine detrital fragments. All samples were dried and ground, placed into tin capsules and their isotopic signatures analysed on an Isoprime mass spectrometer. The ratios of ${ }^{13} \mathrm{C} /{ }^{12} \mathrm{C}$ for all samples were calculated as the relative per mil (\%) difference between the sample and the recognised international standard (Pee Dee belemnite limestone carbonate) and expressed as $\delta^{13} \mathrm{C}$ values.

Differences in the isotope signatures of animals at different positions within each habitat and among sites were tested using a 2-way analysis of variance separately for each species. The 2 factors were position (fixed, 5 levels for crabs, 3 for gastropods) and site (random, 5 levels for crabs, 3 for gastropods). Differences among sites were not of specific interest but were included to allow the variation due to positions to be fully partitioned. Data were checked for homogeneity of variances using Cochran's $C$-test, and no transformations were necessary. Where the position factor was significant, differences among positions were tested using a Student-Newman-Keuls (SNK) test.

\section{RESULTS}

\section{Autotrophs}

The $\delta^{13} \mathrm{C}$ signatures of Sporobolus virginicus varied by $<1 \%$ among habitat positions $\left(\delta^{13} \mathrm{C}\right.$ centre: $-14.7 \pm$ $0.1 \%$; edge: $-15.0 \pm 0.1 \%$ ). There was also little variation $\left(<2 \%\right.$ ) in $\delta^{13} \mathrm{C}$ among mangrove species Avicennia marina $(-27.4 \pm 0.2 \%)$, Ceriops tagal (-28.2 \pm $0.3 \%), \quad$ Rhizophora stylosa (-26.3 $\pm 0.2 \%$ ) and Bruguiera gymnorhiza $\left(-28.2 \pm 0.5 \%\right.$ ). The mean $\delta^{13} \mathrm{C}$ of MPB in the saltmarsh $(-23.0 \pm 0.5 \%$ o was $1.4 \%$ higher than in mangroves $(-24.4 \pm 0.2 \%)$. The $\delta^{13} \mathrm{C}$ of saltmarsh and mangroves did not vary significantly among sites throughout the estuary (overall means shown in Fig. 4).

\section{Consumers}

The $\delta^{13} \mathrm{C}$ signatures of each animal species differed significantly among habitat positions (Fig. 4). Both species of crabs showed the same pattern of $\delta^{13} \mathrm{C}$. The $\delta^{13} \mathrm{C}$ signatures of crabs differed significantly among habitats but not among positions within the same habitat. The $\delta^{13} \mathrm{C}$ values were significantly higher for crabs in the saltmarsh $(-15.2 \pm 0.2 \%$ for Australoplax tridentata, $-16.1 \pm 0.2 \%$ for Parasesarma erythrodactyla) than for those in the mangroves $(-21.1 \pm 0.4$ and -23.1 $\pm 0.2 \%$, respectively; ANOVA, factor position, $\mathrm{p}<$ 0.001 for both species, Fig. 4). The $\delta^{13} \mathrm{C}$ signatures of A. tridentata ( $-15.2 \%$ ) and $P$. erythrodactyla $(-16.2 \%$ ) in the saltmarsh were close to those of Sporobolus virginicus $\left(-14.9 \pm 0.1 \%\right.$ o). The $\delta^{13} \mathrm{C}$ of both species of crabs in the mangrove habitat were higher than those in the mangroves $(-27.6 \pm 0.2 \%$ o). Values for P. erythrodactyla were very similar to those of MPB, whereas $A$. tridentata was slightly enriched relative to MPB.

A significant interaction between position and site was found for both Australoplax tridentata and Parasesarma erythrodactyla (ANOVA, interaction term, p < 0.001 for both species). The source of this variation is attributable to a single site (Site 5, Fig. 5) that had lower $\delta^{13} \mathrm{C}$ values (A. tridentata $-19.5 \pm 1.2 \%$, P. erythrodactyla $-20.2 \pm 1.1 \%$ ) than all other sites (A. tridentata $-17.1 \pm 0.4 \%$, $P$. erythrodactyla $-18.5 \pm 0.4 \%$ ) predominantly due to the lower $\delta^{13} \mathrm{C}$ values of crabs at the edge position. The $\delta^{13} \mathrm{C}$ signatures of both crab species collected at the edge position at Site 5 (A. tridentata $-19.4 \pm 0.7 \%$, P. erythrodactyla $-20.1 \pm 0.6 \%$ ) were significantly lower than those from the other saltmarsh positions at that site $(A$. tridentata $-14.4 \pm 0.1 \%$, $P$. erythrodactyla $-15.5 \pm 0.7 \%$ o).

The $\delta^{13} \mathrm{C}$ signatures of the gastropod Ophicardelus quoyi from the saltmarsh habitat did not differ significantly between the central $(-14.9 \pm 0.2 \%$ o $)$ and intermediate $(-15.8 \pm 0.2 \%)$ positions, but were significantly higher than those of snails from the edge positions $(-17.1 \pm 0.5 \%$ ) (Fig. 4$)$. The $\delta^{13} \mathrm{C}$ of Salinator solida showed the same pattern of variation as for 

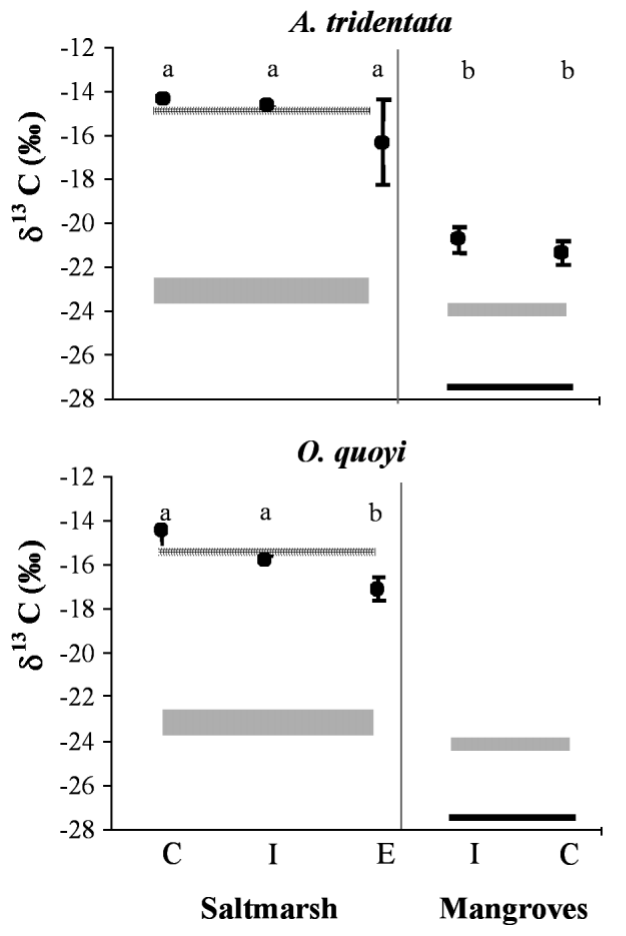
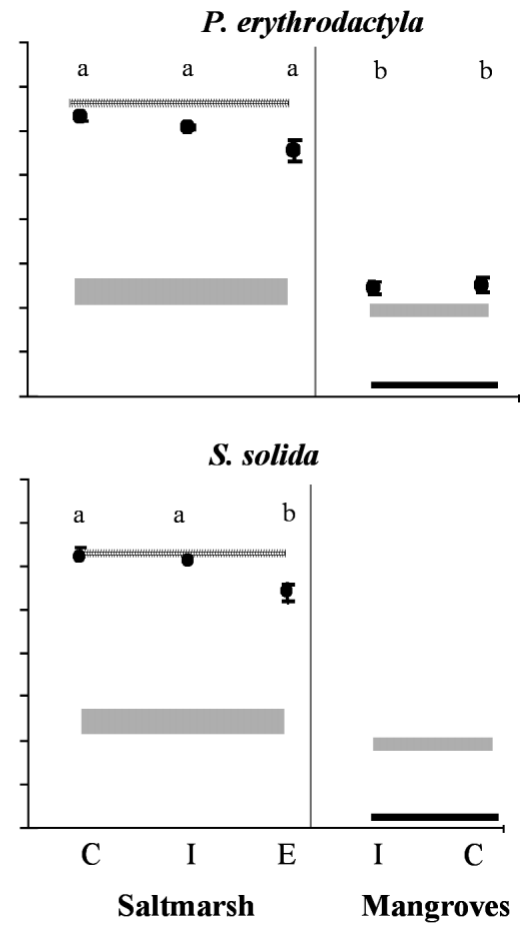

Fig. 4. Carbon stable isotope signatures for autotrophs (mangroves, Sporobolus virginicus and microphytobenthos, MPB), and for each crab (Australoplax tridentata and Parasesarma erythrodactyla) and gastropod (Ophicardelus quoyi and Salinator solida) species across sampling positions. C: centre; I: intermediate; E: edge. Values averaged across the 5 sites $( \pm 1 \mathrm{SE}$; $\mathrm{SE}$ too small to see in some cases). Widths of lines for autotrophs represent \pm 1 SE. Different letters indicate significant differences in ani-mal signatures among positions
O. quoyi, with snails from the central $(-15.2 \pm 0.2 \%)$ and intermediate $(-15.3 \pm 0.1 \%$ o positions not differing but being more enriched than snails from the edge $(-16.8 \pm 0.4 \%$ o) (Fig. 4).

\section{DISCUSSION}

\section{Scales of carbon movement and assimilation}

This study is the first to use stable carbon isotopes to link animal position and carbon source at the fine-scale between adjacent estuarine habitats. Since isotope signatures of all consumers varied with position, our results do not support the coarse-scale model (Fig. 1, Model a) of large-scale carbon movement and assimilation between adjacent saltmarsh and mangrove habitats. Carbon movement and assimilation by the crabs and gastropods in these 2 habitats therefore occurs at scales of $<30 \mathrm{~m}$.

Our results indicate that the scale of carbon movement and assimilation is either towards the lower end of the intermediate model range ( 2 to $15 \mathrm{~m}$ ) or $<2 \mathrm{~m}$ (the fine-scale model). Support for the intermediate model is provided by the $\delta^{13} \mathrm{C}$ of gastropods at all sites and crabs at Site 5. For gastropods, the slight but significant depletion in their $\delta^{13} \mathrm{C}$ signatures at the edge position $2 \mathrm{~m}$ inside the saltmarsh habitat suggests movement and assimilation of carbon across the saltmarsh-mangrove interface. Likewise, crabs at Site 5 showed the same depletion in $\delta^{13} \mathrm{C}$ at the edge position. Animals may also assimilate MPB produced in situ and this may explain the lower $\delta^{13} \mathrm{C}$ signatures at edge positions. In this scenario, the depleted $\delta^{13} \mathrm{C}$ signatures at the edge position for the gastropods and for the crabs at the edge position at Site 5 support more limited carbon exchange (i.e. the fine-scale model) across the saltmarsh-mangrove interface.

The $\delta^{13} \mathrm{C}$ signatures of crabs in the saltmarsh habitat at sites other than Site 5 matched the $\delta^{13} \mathrm{C}$ signature of the salt couch grass Sporobolus virginicus, the macrophyte in their immediate vicinity. Although the $\delta^{13} \mathrm{C}$ signatures of crabs in the mangrove habitat were enriched relative to those of the mangroves, they matched those of the MPB in the mangrove habitat (closely for Parasesarma erythrodactyla, less so for Australoplax tridentata). The $\delta^{13} \mathrm{C}$ signatures of crabs were therefore consistent with the fine-scale model of assimilation of carbon from producers in their immediate vicinity (Fig. 1, Model c). However, the $\delta^{13} \mathrm{C}$ signatures of crabs in the mangrove habitat could also have resulted from a mixture of carbon sources from, for example, a combination of mangrove and salt couch grass, with or without MPB. In this scenario, the signatures of mangrove crabs suggest movement of carbon over larger distances, whilst those of saltmarsh crabs strongly indicate fine-scale movement. Investigating the relative importance of MPB to crabs in mangroves is pivotal to further differentiating among our models of carbon movement. Future work might best examine 

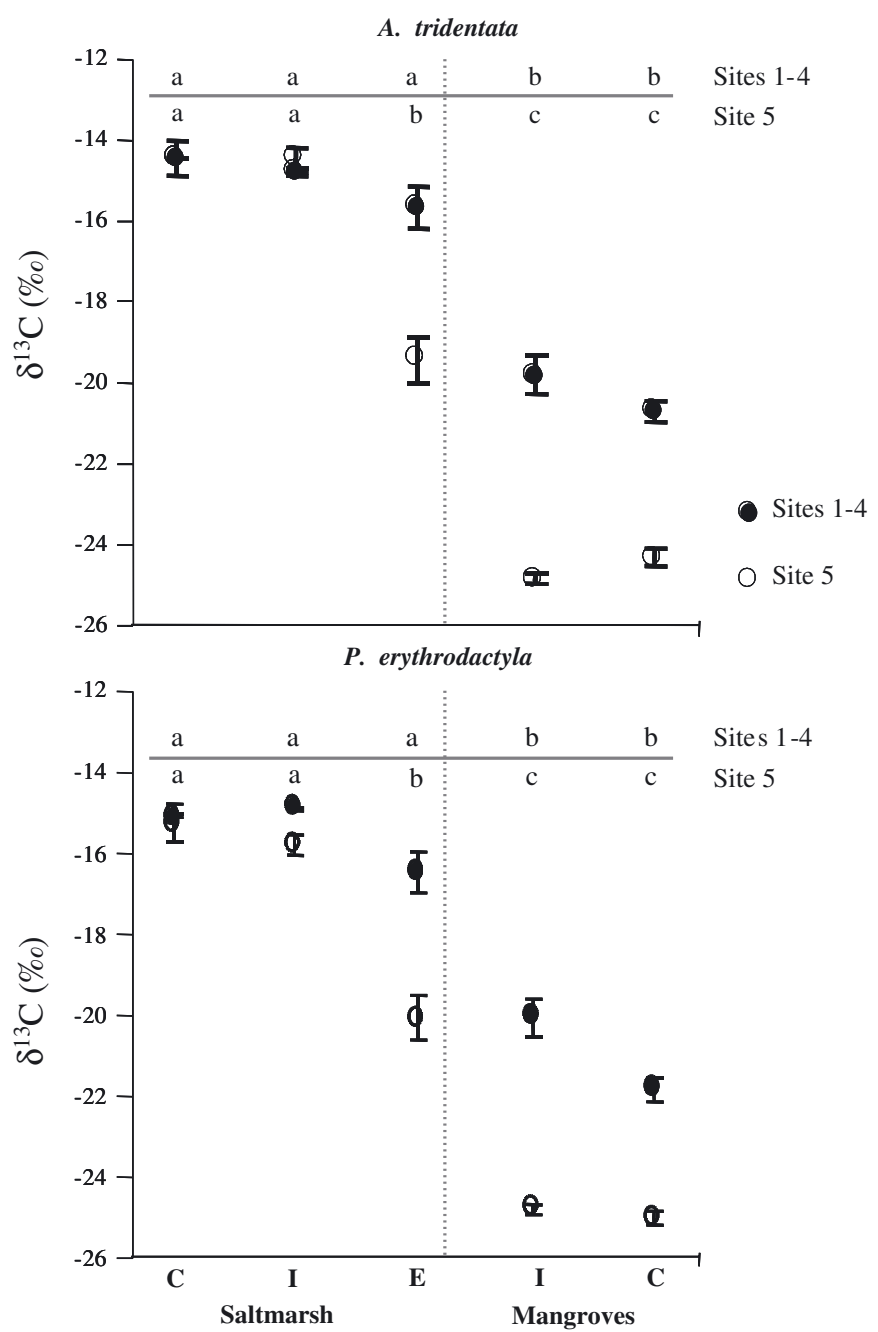

Fig. 5. Australoplax tridentata and Parasesarma erythrodactyla. Mean ( $\pm 1 \mathrm{SE}$ ) isotope signatures at Sites 1 to 4 and Site 5 (separate). Different letters indicate significant differences in isotope signatures among positions. Abbreviations as in Fig. 4

the importance of MPB to mangrove animals using recently developed techniques for manipulating isotopic signatures of algae (e.g. Winning et al. 1999, Carman \& Fry 2002).

The interface between the saltmarsh and mangrove habitats was very useful for testing among our models: although the carbon isotope values of salt couch grass and mangroves were very different, the values for each autotroph within any one habitat were similar at all positions. Elsewhere, the carbon isotope signatures of a single autotroph species adjacent to mangroves have themselves been shown to be affected by proximity to mangroves. For example, in a bay in Kenya, the $\delta^{13} \mathrm{C}$ signatures of seagrass were $9 \%$ lower in seagrass adjacent to mangroves than in seagrass several kilometres away, because of the lower isotope value of the dissolved inorganic carbon generated in the mangroves (Marguillier et al. 1997). The slight depletion of MPB we found in the mangrove relative to the saltmarsh habitat might well result from the same phenomenon. Our test among models for 2 adjacent habitats, focusing on differences among positions rather than on whether mangrove material per se was an important source to animals, also avoided the issue of generalised depletion of carbon values in the whole mangrove biota (France 1998).

The results of this study are in contrast to historical expectations of large-scale carbon movement in aquatic systems but are consistent with a recent study of the movement and assimilation of carbon between adjacent habitats at a smaller scale. Hsieh et al. (2002) analysed the carbon isotopes of ocypodid crabs at sites separated by hundreds of metres. They concluded that ocypodid crabs derive their carbon from the sites in which they reside rather than from sites further away. Ocypodid crabs (Uca arcuata and U. borealis) collected at a creek site were considered to have derived their carbon from MPB, although a mixed diet of algae, particulate organic matter or the detritus of a terrestrial grass was also a plausible source (Hsieh et al. 2002). However, at river sites $600 \mathrm{~m}$ from the creek site, the main source of carbon for these species was the terrestrial grass nearest to the river site. Our own work suggests that even the site-specific work of Hsieh et al. (2002) was at a scale much coarser than the movement and assimilation of carbon by shore crabs, which probably obtain their nutrition from sources in the surrounding few metres.

In this study, the change in $\delta^{13} \mathrm{C}$ signatures between the saltmarsh and mangrove habitats was the same for both crab species and among all sites sampled. However, the isotope signatures of crabs at 1 site (Site 5) were lower at the edge and mangrove positions than at these positions in all other sites. Observations while sampling showed that the edge positions at this marsh appeared to drain more slowly than the edge positions on the other marshes. Whilst this difference in hydrology was not sufficient to influence the isotopic signatures of the plants, it may have influenced the feeding behaviour of the crabs at the edge positions.

\section{Crab and gastropod diets}

Both crab species collected in the saltmarsh in this study appear to derive their carbon from salt couch grass. Crabs in the mangroves may obtain their carbon predominantly from MPB, although their $\delta^{13} \mathrm{C}$ signatures are also consistent with a mixture of carbon sources such as mangroves and salt couch grass, with or without a contribution from MPB. So far, no studies 
have specifically examined the diet of these 2 crab species, but observations of feeding behaviour typically ascribe a wide range of feeding habits to ocypodid and grapsid crabs (Lee 1998).

The feeding habits of grapsid crabs include the harvesting of mangrove leaves from the canopy (Warner 1967) and the consumption of saltmarsh plants (e.g. Spartina densiflora, Iribarne et al. 1997) and mangrove leaf litter (Lee 1997). Sesarmid crabs (e.g. Parasesarma erythrodactyla) are typically considered to be herbivores that carry leaf litter into their burrows (Lee 1998), but recent evidence from gut-content analysis suggests a lack of dietary specialisation for some species (e.g. Sesarma leptosoma) that indicates a generalist mode of feeding and dietary assimilation (Dahdouh-Guebas et al. 1999). However, the $\delta^{13} \mathrm{C}$ signatures of $P$. asperum collected from mangrove habitat were slightly more enriched than those of mangroves (Bouillon et al. 2002), a result similar to that for $P$. erythrodactyla in the current study. The slightly enriched $\delta^{13} \mathrm{C}$ of $P$. asperum relative to those of mangroves was thought to result from a diet comprising a mixture of mangrove material and sediment scrapings.

Ocypodid crabs have been described as feeding on bacteria (e.g. Uca vocans and U. polita, Dye \& Lasiak 1986) or microalgae (e.g. U. dussumieri, U. forcipata, $U$. rosea and $U$. triangularis, Rodelli et al. 1984), and a variety of plant matter including particulate organic matter and terrestrial grass (e.g. U. arcuata and U. borealis, Hsieh et al. 2002). Carbon stable isotope studies of $U$. pugnax in USA saltmarshes found that the signature of crabs closely matches that of the cordgrass Spartina alterniflora (Haines \& Montague 1979, Currin et al. 1995). Even where ocypodids consume plant material, however, it is mostly as detritus, and they are also likely to ingest microbes and microscopic invertebrates.

There is little information on the diets of Salinator solida and Ophicardelus quoyi, but they are generally considered to either graze on microalgae or behave as detritivores (e.g. S. burmana, Rodelli et al. 1984). Microalgae are generally considered an important food source for macrobenthos in saltmarshes (Sullivan \& Moncreiff 1990). In our study, however, the $\delta^{13} \mathrm{C}$ signatures of gastropods in the saltmarsh habitat indicated that they obtain their carbon predominantly from salt couch grass. Analysis of the diet of 2 depositfeeding gastropods, Assiminea japonica and Angustassiminea castanea, revealed that although these snails feed mainly on phytoplankton and benthic algae in the wild, they were nevertheless able to assimilate organic matter from reed detritus under laboratory conditions (Kurata et al. 2001). This demonstrates, at least for these species, that they are physiologically capable of assimilating carbon from grasses.

Seagrass is also present in southern Moreton Bay, seaward of the mangroves, and has an enriched $\delta^{13} \mathrm{C}$ signature $(-12 \%)$ similar to that of saltmarsh grass (Melville \& Connolly 2003). Seagrass carbon could potentially be deposited on the marshes and be utilised by crabs and gastropods directly or indirectly. However, as there was no seagrass in the vicinity of the saltmarsh sites and no seagrass detritus observed at the site, it is unlikely that seagrass contributed much, if at all, to the consumer carbon source. The carbon isotope signatures of phytoplankton ( 20\%) (Fry 1984, Bouillon et al. 2000, Davenport \& Bax 2002) also make it an unlikely source of carbon for consumers residing on the saltmarsh. Truly terrestrial vegetation can show similar isotopic signatures to that of mangroves (e.g. -27 to $-30 \%$, Boon \& Bunn 1994), but the sites used in this study were several kilometres from terrestrial sources, minimising the likelihood of terrestrial vegetation contributing to the isotopic signatures of the consumers. As animal samples were composites of several individuals, it is also possible that differences in individual feeding behaviour, such as animals feeding entirely on MPB at the edge position, will have been undetected. Future studies using $\delta^{13} \mathrm{C}$ values of individual animals would clarify individual feeding behaviour.

Whilst the aim of this study was to examine carbon movement and its assimilation by estuarine invertebrates, the movement of the target animals across habitat boundaries could also explain the observed patterns in $\delta^{13} \mathrm{C}$ (e.g. Hobson 1999). Such movement is considered unlikely for the crabs and gastropods in this study. Little information on the movement of crabs and gastropods is available, but both crab species are considered to be faithful to their burrows, and the gastropods appear to move predominantly vertically within the sediment profile (M. A. Guest pers. obs.). This study used invertebrates of limited mobility that were either detritivores or grazers, to highlight potential carbon movement between adjacent habitats, but the results may have differed had animals of greater mobility and/or different feeding modes been examined. For example, had we examined sedentary filterfeeding bivalves on the marsh, their carbon signature might have reflected that of the water-column phytoplankton produced remotely rather than any in situ production. Further work on animals of differing mobility and feeding modes is therefore needed to achieve a more general conclusion about the scale of carbon movement and assimilation in estuarine systems.

It is possible that carbon may move among habitats at any of the scales presented but not be assimilated by the consumers sampled (Duarte \& Cebrian 1996). Stable isotope analysis of consumers tests only the movement and assimilation of carbon. As this study set out to determine the trophic importance of discrete habitats over different spatial scales, only the movement 
and assimilation of carbon has been examined. Movement of carbon that does not contribute to trophic dynamics has therefore not been considered. In this study, carbon isotope results from 2 types of estuarine invertebrates showed that the movement and assimilation of carbon occurs at scales much smaller than originally conceived in theories about the movement of carbon from inshore to offshore habitats.

Acknowledgements. We thank J. Gilroy, D. Gorman, A. Melville and J. Oakes for field assistance, K. Preston for laboratory assistance and T. Gaston and A. Melville for comments on the manuscript. This work was funded by the CRC for Coastal Zone, Estuary and Waterway Management.

\section{LITERATURE CITED}

Boon PI, Bunn SE (1994) Variations in the stable isotope composition of aquatic plants and their implications for food web analysis. Aquat Bot 48:99-108

Bouillon S, Mohan PC, Sreenivas N, Dehairs F (2000) Sources of suspended organic matter and selective feeding by zooplankton in an estuarine mangrove ecosystem as traced by stable isotopes. Mar Ecol Prog Ser 208:79-92

Bouillon S, Koedam N, Raman AV, Dehairs F (2002) Primary producers sustaining macro-invertebrate communities in intertidal mangrove forests. Oecologia 130:441-448

Carman KR, Fry B (2002) Small-sample methods for $\delta^{13} \mathrm{C}$ and $\delta^{15} \mathrm{~N}$ analysis of the diets of marsh meiofaunal species using natural-abundance and tracer-addition isotope techniques. Mar Ecol Prog Ser 240:85-92

Chong, VC, Low, CB, Ichikawa T (2001) Contribution of mangrove detritus to juvenile prawn nutrition: a dual stable isotope study in a Malaysian mangrove forest. Mar Biol 138:77-86

Currin CA, Newell SY, Paerl HW (1995) The role of standing dead Spartina alterniflora and benthic microalgae in salt marsh food webs: considerations based on multiple stable isotope analysis. Mar Ecol Prog Ser 121:99-116

Dahdouh-Guebas F, Giuggioli M, Oluoch A, Vannini M, Cannicci S (1999) Feeding habits of non-ocypodid crabs from two mangrove forests in Kenya. Bull Mar Sci 64:291-297

Davenport SR, Bax NJ (2002) A trophic study of a marine ecosystem off southeastern Australia using stable isotopes of carbon and nitrogen. Can J Fish Aquat Sci 59:514-530

Deegan L, Garritt RH (1997) Evidence for spatial variability in estuarine food webs. Mar Ecol Prog Ser 147:31-47

Dittel AI, Epifanio CE, Schwalm SM, Fantle MS, Fogel ML (2000) Carbon and nitrogen sources for juvenile blue crabs Callinectus sapidus in coastal wetlands. Mar Ecol Prog Ser 194:103-112

Duarte CM, Cebrian J (1996) The fate of marine autotrophic production. Limnol Oceanogr 41:1758-1766

Dye AH, Lasiak TA (1986) Microbenthos, meiobenthos and fiddler crabs: trophic interactions in a tropical mangrove sediment. Mar Ecol Prog Ser 32:259-264

France R (1998) Estimating the assimilation of mangrove detritus by fiddler crabs in Laguna Joyuda, Puerto Rico, using dual stable isotopes. J Trop Ecol 14:413-425

Fry $\mathrm{B}(1984){ }^{13} \mathrm{C} /{ }^{12} \mathrm{C}$ ratios and the trophic importance of algae in Florida Syringodium filiforme seagrass meadows. Mar Biol 79:11-19

Haines EB, Montague CL (1979) Food sources of estuarine invertebrates analysed using ${ }^{13} \mathrm{C} /{ }^{12} \mathrm{C}$ ratios. Ecology 60:48-56

Hobson KA (1999) Tracing origins and migration of wildlife using stable isotopes: a review. Oecologia 120:314-326

Holt RD (2002) Food webs in space: on the interplay of dynamic instability and spatial processes. Ecol Res 17:261-273

Hsieh H, Chen C, Chen Y, Yang H (2002) Diversity of benthic organic matter flows through polychaetes and crabs in a mangrove estuary: $\delta^{13} \mathrm{C}$ and $\delta^{34} \mathrm{~S}$ signals. Mar Ecol Prog Ser 227:145-155

Iribarne O, Bortolus A, Botto F (1997) Between habitat differences in burrow characteristics and trophic modes in the southwestern Atlantic burrowing crab Chasmagnathis granulata. Mar Ecol Prog Ser 155:137-145

Kurata K, Minami H, Kikuchi E (2001) Stable isotope analysis of food sources for salt marsh snails. Mar Ecol Prog Ser 223:267-177

Lee SY (1995) Mangrove outwelling - a review. Hydrobiologia 295:203-212

Lee SY (1997) Potential trophic importance of the faecal material of the mangrove sesarmine crab Sesarma messa. Mar Ecol Prog Ser 159:275-284

Lee SY (1998) Ecological role of graspid crabs in mangrove ecosystems: a review. Mar Freshw Res 49:335-343

Loneragan NR, Bunn SE, Kellaway DM (1997) Are mangroves and seagrasses sources of organic carbon for penaeid prawns in a tropical Australian estuary? A multiple stable isotope study. Mar Biol 130:289-300

Marguillier S, Van der Velde G, Dehairs F, Hemminga MA, Rajagopal S (1997) Trophic relationships in an interlinked mangrove-seagrass ecosystem as traced by $\delta^{13} \mathrm{C}$ and $\delta^{15} \mathrm{~N}$. Mar Ecol Prog Ser 151:1-3

Marquet PA, Fortin MJ, Pineda J, Wallin DO and 5 others (1993) Ecological and evolutionary consequences of patchiness: a marine-terrestrial perspective. In: Powell $T$, Levin S, Steele J (eds) Patch dynamics in marine and terrestrial environments. Springer-Verlag, Berlin, p 277-304

McCutchan JH, Lewis WM, Kendall C, McGrath CC (2003) Variation in trophic shift for stable isotope ratios of carbon, nitrogen and sulfur. Oikos 102:378-390

Melville AJ, Connolly RM (2003) Spatial analysis of stable isotope data to determine primary sources of nutrition for fish. Oecologia 136:499-507

Odum EP (1979) Factors controlling the flux of particulate organic carbon from estuarine wetlands. In: Livingston RJ (ed) Ecological processes in coastal and marine systems. Plenum Press, New York, p 69-79

Peterson BJ, Fry B (1987) Stable isotopes in ecosystem studies. Annu Rev Ecol Syst 18:293-320

Polis GA, Anderson WB, Holt RD (1997) Toward an integration of landscape and food web ecology: the dynamics of spatially subsidized food webs. Annu Rev Ecol Syst 28: 289-316

Rodelli MR, Gearing JN, Gearing PJ, Marshall N, Sasekumar A (1984) Stable isotope ratio as a tracer of mangrove carbon in Malaysian ecosystems. Oecologia 61:326-333

Sullivan MJ, Moncreiff CA (1990) Edaphic algae are an important component of saltmarsh food-webs: evidence from multiple stable isotope analyses. Mar Ecol Prog Ser 62:49-159

Taylor D, Allanson BR (1995) Organic carbon fluxes between a high marsh and estuary, and the inapplicability of the outwelling hypothesis. Mar Ecol Prog Ser 120:263-270

Warner GF (1967) The life history of the mangrove tree crab, Aratus pisoni. J Zool 153:321-325

Winning MA, Connolly RM, Loneragan NR, Bunn SE (1999) ${ }^{15} \mathrm{~N}$ enrichment as a method of separating the isotopic signatures of seagrass and its epiphytes for food web analysis. Mar Ecol Prog Ser 189:289-294 